\title{
Tuti, Poe, Pontu ja minu teised lemmikud
}

Ülo Siimets

Igal inimesel on loomad, loomakesed, linnud või kalakesed, kellega ta elus kokku puutub. Need kuuluvad talle, tema tuttavatele, sõpradele, lastele. Tavaliselt lõppeb lemmiku pidamine kurvalt, sest kahjuks on väikeloomade eluaeg märkimisväärselt lühem kui inimestel.

Kui paluti kirjutada lugu lemmikloomadest, oli mul esialgu tunne, et ega midagi olegi kirjutada. Kui aga hakkasin meenutama lapsepõlve, koorus hämarusest välja üksjagu huvitavaid lemmikloomadega seotud eluseiku.

\section{Tuti}

Minu esimesed lapsepõlvemälestused kuuluvad aega, kui olin umbes kolme ja poole aastane. Mu isa oli koolidirektor. Elasime Räpina keskkooli peamajas. Vana kool asus Oktoobri tänavas TartuVärska maantee ääres Võhandu jõe kaldal vana puusilla lähedal.

Meil oli mitmeid koduloomi ja -linde: lehmad, sead, kanad, rääkimata kooli ümber jalutavatest hiirepüüdjatest, kes elasid lauda juures ja külastasid aeg-ajalt kas meie või kooltädi kööki.

Ühel päikesepaistelisel maihommikul tuli isa laadalt mitme valgete aukudega pappkarbiga. Karpidest kostis ärevat piuksumist. Põlesime uudishimust. Isa tõi kooli puidutöökojast suure puukasti, mille põhi oli kaetud höövlilaastudega. Ta pani kasti maha ja lõikas noaga katki nööri, mis karpe koos hoidis. Võttis kaane ühelt pappkarpidest ja meile avanes suurepärane vaatepilt. Karbis siblis kümme kollast kerakest, kes kasti asetatuna paterdasid ärevalt siia sinna.

Isa oli ostnud kolmkümmend pardipoega. Nendest ühel olid püstised suled pea peal. Võtsin ta sülle ja silitasin pead. Suled pea peal jäid kangekaelselt püsti. Piilu piiksus hirmunult ja püüdis lahti rabelda. Andsin talle nimeks Tuti. Ema käskis Tuti kasti tagasi panna, et ta algul harjuks meiega. Nii tegingi.

http://haldjas.folklore.ee/tagused/nr31/ylolem.pdf 
Pardipoegi toideti algul peeneks hakitud keedetud kanamunadega. Hiljem hakati andma tanguteri, hakitud peedilehti, leiba jne. Kuna kastis käis hirmus tõuklemine ja toidu pärast kaklemine, püüdsin oma Tutit ise hoolikalt sööta. Tõstsin ta kastist välja ja panin talle eraldi toitu taldrikule. Pardipojad kasvasid kiiresti ja Tuti kasvas minu nuumamise tõttu eriti hästi. Suled pea peal jäid aga miskipärast ikka turri. Varsti lasti piilud juba jõele ujuma. Sealt otsisid nad endale ise toitu. Aeg-ajalt kutsuti neid sööma kaldale, kus jagati leivatükke.

Mina toitsin oma Tutit täiendavalt. Ta harjus minuga ja hakkas mind pärast söötmist kodu suunas saatma. Vahel istusin jõe ääres. Kui Tuti oli kõhu täis söönud, hakkas ta sulgi puhastama. See oli nii naljakas, kuidas ta nokaga klōbistades kiiresti tiiva all nokitses, vaatas ringi, ega midagi kahtlast ole, ja nokitses uuesti. Minuga oli ta nii harjunud, et lasi ennast sülle võtta ja silitada. Teised pardid ei tulnud mulle kunagi nii lähedale. Kui tahtsin neid puutuda, lubasid nad mind endast umbes poole meetri kaugusele ja lasid siis prääksudes jalga. Mõned pardid hoidsid koguni paari meetri kaugusele.

Ühesõnaga - Tuti oli eriline part. Minu kutse peale tormas ta tiibade vehkides, vee lainetades ja prääksudes kalda suunas, teised hilinemisega järel. Käisin mitu korda päevas jõe ääres, leivatükk taskus. See saigi minu Tutile saatuslikuks.

Räpina lähedal Köstrimäel elas parun von Sieversi endine kutsar Viia Frits. Rahvas kutsus teda Viia Pritsuks. Ta oli koheva juuksepahmakaga pikk kõhn mees. Vanust oli tal vist üle kuuekümne aasta, kui tal esimesed juuksed halliks läksid. Teiseks tunnuseks oli see, et ta oli pidevalt purjus. Tavaliselt sõitis ta ringi oma hobusega, istudes vankris üle vankriääre asetatud laual, üks jalg üle vankriääre. Nagu ta ise rääkis, olla tema hobune nii tark, et isegi siis, kui mees väga purjus on ja vankris magab, viib hobune ta koju, kus naine ja lapsed ta tuppa talutavad. Põhiliselt teenis ta igapäevast leiba kolhoosis hobusemehena. Selle töö kõrvalt kündis, äestas, vedrutas jne inimeste põlde. Ka teenis ta suvel kartulimaade vaheltharimise, heinaveo ja muude töödega. Teda kutsuti ka koduloomi tapma. Põhiliselt käis ta sigu torkamas, aga kustutas eluküünla vajadusel ka lammastel, kodulindudel jne.

Ühel päeval oli ta istumas meie köögis. Isa, kes direktori ameti kõrvalt koolis ka keemiat ja füüsikat õpetas, pakkus Pritsule 
süüa ja koolilaborist toodud piiritust. Mehed ajasid omavahel juttu. Prits naljatles meiega. Võttis mind sülle, kutsus oma pojaks ja lubas hobusega sõitma viia. Mul oli uhke tunne, et mind hobusega sõitma lubati viia. Teistele lastele kutset hobusega sõitma tulla ei olnud. Tegelikult aeg-ajalt sõidutaski ta mind hobusega. Ükskord pandi mind isegi pärast kartulite vaheltharimist, kui hobune adra eest lahti rakendati, hobuse selga. Sain siis mõned tiirud sõita ja pärast võisin sellega tükk aega teiste laste ees kiidelda.

Seekord aeti meid lõunauinakule. Meil oli kodus komme, et lapsed pidid päeval magama. Ka isa ise magas aeg-ajalt päeval, lastes leiba luusse. Siis ei tohtinud keegi tema und häirida ja pidid olema oma toas seni, kuni isa ärkas ja toauks lahti tehti.

Pärast magamist haarasin köögist leivaviilu ja tormasin jõe äärde. Kutsusin heledal häälel: "Tuti, Tuti, Tuti!"

Pardid tormasid kalda suunas, aga Tutit nende hulgas ei olnud. Andsin partidele leiba ja otsisin silmadega pardiparve hulgast oma sõpra. Tutit ei olnud. Söötsin leiva partidele ja läksin nutta tihkudes toa poole kaebama, et Tuti on kadunud. Ema arvas, et küllap ta jalutab kusagil ringi. Isa ütles, et oli hommikul rebast näinud lauda taga luusimas, võib-olla viis Tuti ära.

Õhtuks anti meile süüa pardipraadi värskete kartulitega. Maitsev oli.

Mina käisin mitu korda päevas oma Tutit otsimas, kuid ei näinud teda enam kunagi. Söötsin aeg-ajalt parte, aga huvi nende vastu oli kadunud - õigemini meenutasid nad Tutit.

Siis panin tähele, et iga kord, kui Prits meil külas käis ja isaga köögis piiritust jõi, oli lõunaks pardipraad. Hakkasin aimama, et ka Tuti praeti ära, aga ei suutnud seda uskuda. Täiskasvanutest ei rääkinud keegi tõtt. Kõik ütlesid, et rebane viis ära - näed, kogu aeg jääb pardiparv väiksemaks. Rebane passib kõrkjates. Kui mõni part kõrkjatele liiga lähedale tuleb, hüppab pardile kõrri ja tirib metsa.

Mina aga mõtlesin, et huvitav, miks ta kanakarjast mööda käib ja neid ei puutu. Kanu ei kadunud ju kuhugi.

Rebane käis meil külas seni, kuni pardid olid otsas. Siis enam ei tulnud. Kanad ei hakanudki teda huvitama.

Kui järgmisel kevadel pardipojad toodi, ma enam endale lemmikut ei võtnud. Söötsin kõiki piilusid ühtemoodi, ja ega tutiga pardipoega uute tibude hulgas olnudki. 


\section{Varblane}

Ma ei tea, kas süütundest või niisama heast südamest, kinkis isa, märgates minu huvi elava looduse vastu, mulle väikese varblasepoja. Kooli koduloonurgast toodi väike puur. Söötsin lindu tanguteradega ja vahetasin puuris vett. Varblasepoiss kasvas jõudsalt. Võtsin ta vahetevahel puurist välja ja silitasin tal pead. Tavaliselt sai ta varsti puuri tagasi pandud.

Peagi oli linnuke juba vana varblase suurune. Rääkisin naabripoistele, et mul on kodus väikene varblane. Nemad tahtsid näha. Võtsin varblase puurist välja ja viisin õue. Naabripoisid ootasid mind puuriida juures. See oli esimene kord, kui lind pärast kinnipüüdmist õue sai. Kõik silitasid varblast. Värvuke värises peos. Võibolla silitas mõni lastest teda liiga tugevasti, aga ühel hetkel haaras varblane nokaga minu peopesast kinni. See oli nii valus, et lasin peo lahti. Varblane lipsas kahe puuriida vahele ja sealt puuriida sisse.

Ja läinud see linnuke oligi. Meel oli kurb. Peopesas oli naha all mitu aastat tume verevalum - pisikene, nööpnõelapeasuurune plekk nagu tätoveering meenutamaks minu varblasepoissi. Käisime teiste lastega ikka puuriida juures. Puistasime sinna süüa, aga varblast me enam ei näinud. Tegelikult tuli sinna ju mitmeid varblasi, aga kas ka minu oma nende hulgas oli, seda ma ei tea.

\section{Kingitus kaksikutele}

Järgmisel kevadel oli pastoraadi tiigi peal metspartide pesakond. See tiik oli umbes viiskümmend meetrit pikk ja servadest peaaegu kinni kasvanud. Tiik polnud kuigi sügav, aga selle põhjas oli paksult muda. See oli kooli territoorium - endises pastoraadis asus üks Räpina keskkooli osakond.

Isa ja onu Prits püüdsid pardipoegi kätte saada. Nad võtsid aluspükste väele ja haarasid kooli loodusloo kabinetist toodud liblikavõrgud (kahvad) kätte. Onu Prits ütles mulle, et ta püüab oma pojale pardikese. Mina läksin kalda peale vaatama, kuidas see toimub. Pardipojad ei jäänud muidugi ootama, millal nad kinni püütakse. Kohe tormasid nad, emapart ees, kõrkjatesse. Mehed neile järele. Vesi vahutas ja muda lendas. Pardipojad tormasid mitmesse ilma- 
kaarde laiali. Siis prooviti neid kokku ajada nii, et üks mees tuli ujudes ühelt, teine teiselt poolt tiiki, liblikavõrk vart risti hammaste vahel. Pardipoja lähedale jõudes lasti jalad põhja, haarati kahv ja püüti sellega linnupoega tabada. Enamasti olid pardikesed kiiremad kui mehed. Tiigis oli muda üles keeratud ja vesi läikis rasvaselt.

Tiigi ühest küljest läks mööda alevi peamine maantee. Tee peale kogunes palju kohalikest elanikest uudistajaid. Paljud jagasid kaldalt lahkesti nõuandeid. Ühed karjusid: "Minge paremalt!", teised: "Minge vasakult!", kolmandad: "Vaadake, sealsamas teie juures kõrkjates on üks!" Mehed rabelesid, rahvas karjus ja naeris. See oli tõeline tsirkus.

Püüdjad oli üleni mudaga koos, ainult valged silmamunad läikisid porises näos nagu Mooramaa meestel.

Lõpuks olid mehed ja pardipojad väsinud. Pardipojad vist rohkem kui mehed, sest kaks neist õnnestuski kätte saada. Pardikesed pandi spetsiaalselt kaasa võetud kasti. Mehed loputasid ennast kõrvalasuvas jões suurest mudast puhtaks, võtsid riided käe peale ja marssisid uhkelt kooli peahoone suunas. Ka rahvas läks käratsedes laiali. Hulk aastaid hiljem meenutas mõni kohalik inimene: "Ma mäletan, kuidas su isa pastoraadi tiigis parte püüdis. Küll sai nalja."

Jõuti kooli abihoone juures asuva heinaküüni juurde. Selle alla toodi suur hapukapsa- või soolalihatünn. Tünn täideti lähedal olevast kaevust puhta veega. Pardipoegadel kärbiti tiivasulgi, et nad ära ei lendaks, ja lasti veetünni lahti. Direktori kaksikutel pidi varsti sünnipäev tulema. Seega oli üks pardipoeg kingituseks mulle ja teine minu kaksikõele.

Mehed läksid uhkelt sauna kütma ja õlut jooma. Jäime koos teiste lastega kingitust vaatama. Isa laskis kaugemalt vaadata, et las harjuvad meiega. Tegimegi nii. Ilusad kirjud pardipojad olid. Sulistasid tünnis ega teinud meist väga väljagi. Kahjuks need piilud ei elanudki meie sünnipäevani.

Kui järgmisel päeval heinaküüni tulime, hulpis vee peal kaks kirjut sulekobarat, pea vee all. Kurvastasime väga. Isa ütles, et ju see tünn eraldas liiga palju soola. Pardikesed tahavad puhast vett, see vesi ilmselt nii puhas ei olnud.

Korraldasime pardikeste matused. Hauad kaevasime kooli õunapuuaeda suurte puude alla. Panime hauapõhja takjalehe ja selle peale lilledest asemed. Asetasime pardikesed lilledele. Peale pani- 
me pardikestele suured takjalehed. Hauad ehtisime lilledega. Väiksemad õed lahistasid lausa nutta. Kurb oli kõigil.

\section{Minu kalad}

Ühel suvepäeval otsustasid minust mõni aasta vanemad naabripoisid minna kalale. See ei olnud tavaline kalastusretk. See oli kalastusretk Kanajala sohu. Kanajala soo asus koolimajast paar kilomeetrit Mehikoorma poole. Soo oli alati poiste huviorbiidis olnud. Seal oli nii põnev. Astusid üle soo tehtud puitlattidest purde servalt maha ja olid kohe nagu teises maailmas. Kõik õõtsus ja lainetas jalge all. Põnevust lisasid asjale veel jutud, kuidas üks või teine oli sohu läinud ja ära kadunud. Kuidas soolaukad üksikuid neelavad ja kuidas hukkunute hinged öösel uusi ohvreid mülkasse meelitavad.

Läksime sohu hommikul kella kümne ajal. Kõik oli veel kastest märg. Käisime üksteise taga, et mitte ootamatult salalaukasse sattuda. Vanemad ja kasvult suuremad poisid - vennad Lembit ja Ilver Vosmi - kõige ees, nende järel Ennok Kõllo ja siis mina kui kõige noorem ja kõige pisem. Raja kõrvalt napsasime eelmise aasta jõhvikaid, mis tundusid eriliselt head. Igatahes olid nad maitsvamad kui kodus sahvris olevad. Liikumist raskendasid meid pidevalt ründavad tavalised ja hallid parmud, või nagu kohalikud neid halle kutsusid, pimedad parmud. Mõisakülas kutsuti selliseid lätlasteks.

Jõudsime väikese sootiigi juurde. Suuremad poisid asusid kohe asja kallale. Nad võtsid riidest lahti ja läksid alasti tiiki. Ka aluspüksid võeti ära, et need mudaseks ei saaks. Soos tüdrukutest pealtnägijaid niikuinii ei olnud - milleks siis püksid muda täis ajada. Tiigis oli vesi poistele rinnuni. Poisid hakkasid vees ringi tiirutama ja jalgadega peksma. Nii ajasid nad vee mudaseks. Kaladel tuli õhupuudus ja nad pistsid oma suu hingamiseks vee peale. Mina seisin kaldal ja juhendasin, kuskohal mõni kalanina nähtavale ilmus. Seepeale püüti kiiresti seda kala krabada. Enamasti see isegi õnnestus. Püütud kalad visati soosamblale.

Vennad Vosmid olid võtnud kaasa viieliitrise piimanõu, mis enne tiiki minekut oli tiigiveega täidetud. Minu ülesanne oli ühelt poolt kalade kokkukorjamine, teiselt poolt kalda pealt osutamine, kus kalad on. Suured läksid kuhja, väikesed piimanõusse. Väikesest tiigist saime ootamatult palju kalu. Seal oli kokri, linaskeid, hauge ja väikesi latikaid. 
Pärast kalastamist jagati kalad nelja hunnikusse. Iga poiss ajas oma kalad pajuoksa otsa ja pidi ise oma saagi koju tassima. Väikesed kalad võttis Lembit piimanõuga käe otsa ja viis enda poole. Vees olnud poisid pesid ennast suures jões puhtaks.

Marssisin uhkelt koju, pajuoks kaladega seljas. Viisin kalad tähtsalt kööki, kus ma nad pesukaussi asetasin. Terve pere käis vaatamas, kui tubli kalamees ma olen. Pidin kõigile jutustama, kuidas kalapüük sootiigis käib. Vennal oli kahju, et ta ei olnud viitsinud naabripoistega kaasa tulla. Koolitädi - Vaasi-tädi - puhastas ja praadis kalad ära. Maitsvad olid.

Võtsin kolmeliitrise piimanõu ja läksin Vosmide poole. Nüüd jagati ka väikesed kalad neljaks. Suuremad poisid kasutasid neid undade ja õngede otsas elussöödana suurte haugide püüdmiseks. Mina viisin kalakesed koju. Täitsin pesuvanni jõeveega ja lasin kalad lahti. Neid oli mitukümmend. Nii tore oli vaadata, kuidas väiksed kalad vannis ujusid. Need olid sama liiki kalad nagu suuredki, mis pannile läksid.

Järgmiseks hommikuks oli osa väikestest haugidest surnud. Andsin need kassile. Ema ütles, et tuleb vett vahetada, et muidu tekib hapnikupuudus. Vahetasin vannivee, aga see ei aidanud. Järgmisel hommikul olid vannis väikesed haugid ja latikad, kõhud ülespidi. Vahetasin jälle vee.

Kolmandal hommikul olid kõik väiksed haugid surnud, latikatestki oli elus vaid paar. Vahetasin jälle vannivee ära. Nädala pärast oli elus ainult viis väikest kokre. Panin nad kolmeliitrisse klaaspurki ja käisin iga päev jõe ääres vett vahetamas. Kalad elasid ilusti minu magamistoa laual. Söötsime neid ussikestega. Suvi möödus.

Ühel korral olin aga purgivee vahetamisel hooletu. Purk kaladega läks veevõtmisel vastu veealust kivi ja purunes. Kalad ujusid rõõmsalt vabadusse. Rohkem ei ole ma kalakasvatusega tegelnud. Käisime küll veel mitmeid kordi soos kalal, aga väikseid kalu ma endale enam ei võtnud -jätsin suurematele poistele unnakaladeks.

\section{Parun von Sieversi lossikass ja tema kaasa Kirri}

Nagu eespool kirjutasin, elasid meil lehmalauda juures kassid. Palju neid seal oli, ma ei tea, aga sinna kogunesid kahe maja kassid. Erilist suhtlemist mul nendega ei olnud ja ma isegi ei tea, kas neil 
ka nimed olid. Üks kassidest oli kindlasti emane, sest ühel novembrikuu hommikul tuli ta näugudes lauda poolt toa suunas. Lumi oli juba maas ja külma umbes kümme kraadi. Emakassi järel vudis valge-mustakirju kassipoeg. Kassiema kõndis mõned sammud, jäi seisma ja näugus. Kassipoeg vudis talle järele. Nii see asi kordus. Lauda juurest koolimajani oli paarsada meetrit.

Kelgutasime kooliõuel. Minu kõige noorem õde Maret, kes oli vaevalt rääkima õppinud, hõikas: "Näe, poe!" Vaatasime kõik osutatud suunas ja nägime eelkirjeldatud vaatepilti.

Maret tahtis ütelda "Näe, poeg!", aga välja tuli Poe. Tormasime kohe kassi juurde ja ma haarasin pisikese kiisu sülle. Jooksime toa suunas. Vaasi-tädi oli köögis ja imestas väga, kui me kassipojaga tuppa ilmusime.

"Huvitav," ütles ta, "kevadised pojad uputati ära, aga see kass on osanud ühe uue muretseda ja seda nii kaua varjata. Uputamiseks on ta juba liiga suur."

Kassipoeg saigi endale nimeks Poe. Et ilm oli külm, lubati tal magada pliidi juures. Lastele tõi Poe rõõmu. Panime paberlehvi nööri taha ja jooksime majas ringi. Joosta oli meil hea, sest köögist läksid uksed mõlemasse tuppa ja toad olid ka omavahel ühenduses. Nii oli võimalik joosta ringiratast. Poe kasvas jõudsasti. Tal meeldis väljas olla. Kevadel läks ta lauda juurde ja tagasi enam ei tulnud. Aeg-ajalt nägime teda, kui ta köögis söömas käis - iga kord oli ta suuremaks kasvanud. Varsti oli temast saanud ümbruskonna suurim kõuts, kes hoidis teisi kasse oma tugeva käpa all.

Isa suri augusti lõpul. Olin saanud augusti algul seitsmeseks ja hakkasin sügisel käima koolis. Juba septembri lõpul tõsteti meid koolimajast välja teise, väiksemasse kahetoalisse korterisse, sest koolimaja korter anti uuele koolidirektorile. Kooliõpetajast emal justkui ei olnud vaja suurt korterit, mis sest, et tal oli kuus last.

Uus maja, kuhu meile korter anti, oli mäe otsas Räpina aiandustehnikumi peahoone Sieversi (Sillapää) lossi väravas. Lossini oli meie majast sadakond meetrit. Kõrvalmajas mäe all asusid miilitsajaoskond, julgeolek ja kohalik kartser - või nagu meie kutsusime - vangla. Meie kõrvalkorteris elas miilitsaülem kapten Eriste. Majas elas veel teisi riigitähtsaid kodanikke.

Võtsime Poe kaasa, aga talle ei meeldinud uues kohas. Ümbruskonnas olid võõrad kassid, kellega ta oli sunnitud kogu aeg võimu pärast võitlema. Eriti oli ta tülis meie maja ülakorrusel elava kohaliku KGB ülema Bachmanni kõutsiga. See oli suur must valge ma- 
niskiga natukene ületoidetud loom. Kahtlemata oli ta tugev ja Poele vääriline vastane. Kas oli selles süüdi Poe või mõni teine kass, aga varsti pärast meie Mitšurini tänavasse kolimist ja mitmeid raskeid võitlusi jäi must kõuts ühest silmast pimedaks. Poe oli ka pidevalt räsitud ja siit-sealt katki ning lakkus vahetpidamata oma haavu. Talle ei meeldinud vist see pidev kaklemine.

Kuigi meie uus elupaik oli vanast koolist üsna kaugel teisel pool paisjärve, leidis Poe varsti tee kooli juurde tagasi ja asus elama heinaküüni. Oli ta ju kooli piirkonna kasside valitseja. Käisime tal seal järel ja tõime taas uude korterisse. Poe sõi hea meelega kõhu täis head ja paremat, mida lapsed talle suure õhinaga pakkusid. Polnud nad teda ju ammu näinud ja igaüks tahtis kassile meeldida. Ennast täis söönud, vupsas Poe diivanile, pesi end hoolega puhtaks ja jäi magama. Mõne päeva pärast oli ta jälle kooli juures. Nii see muudkui kordus.

Räpina üks tähtsamaid ettevõtteid oli paberivabrik. Käisime kooliga seal korduvalt ekskursioonil. Ühe ekskursiooni ajal pudenes paberihunnikust välja hiirepesa. Sain ühe hiirepoja kätte ja hoidsin kuni ekskursiooni lõpuni peos. Ta oli nii kaunis, õrnade hallide karvadega. Kui koju jõudsin, magas Poe minu voodi peal. Näitasin talle hiirekest. Poe tegi ühe silma lahti ja sulges uuesti. Paistis, et tal ei ole mingit huvi hiirepoja vastu. Panin hiirepoja voodile padja alla ja läksin kööki leiva järele, et hiirekesele süüa anda. Tagasi tulles nägin Poed voodil minu padja juure seismas ja keelt limpsamas. Minu tulles läks kõuts oma kohale tagasi, heitis kõhuli ja minust välja tegemata hakkas oma käppi lakkuma nagu poleks midagi juhtunudki. Tõstsin padja ülesse. Hiirepoega ei olnud enam. Ainult väike vereplekk tekil reetis, mis oli temast saanud. Teha ei olnud enam midagi. Keda sa ikka kirud, kui ise loll oled.

Varsti oli Poe jälle tagasi kooli juures. Minu õed tõid ta tagasi.

Miilitsaülema perekond võttis endale väikese kirju kassipoja, kes sai nimeks Kirri. Ega ta väga suureks kasvanudki, jäigi väikest kasvu kassiks. Kevadel sündisid tal pojad. Need hakkasid juba koridoris ringi vudima ja siis juhtus midagi kohutavat. Nii armas, väike kiisu nagu Kirri oli, murdis ta siiski oma pojad maha. Tulime koolist ja nägime, kuidas ta koridoris nendest ühte sõi. Teised pojad lebasid murtuna emakassi kõrval. Naabrilapsed andsid oma kassile kõvasti naha peale. Miilitsaülem pistis Kirri karistuseks kartulikotti ja viis mootorratta külgkorvis Veriora lähedale metsa, nii ta vähemalt ütles. 
Möödus kolm nädalat ja Kirri oli kodus tagasi. Kõik imestasid. Kohast, kuhu ta viidi, oli Räpinasse oma 15 kilomeetrit. Kass tuli koju ja hakkas ennast näugudes perenaise jalge vastu nühkima. Ta oli kõhnaks jäänud, lausa luu ja nahk. Pereema leidis, et kass on oma karistuse saanud ja kuna ta nii armsalt pereema ees lipitses, siis viimane tegi otsuse: "See kass on nii tark, et leidis kaugelt metsast tee koju. Las ta siis jääb siia." Loomulikult oldi temaga nõus.

Kirrist sai Poe kaasa. See oli võib-olla põhjuseks, miks Poe enam kooli juurde tagasi ei läinud. Võib-olla oli ka põhjuseks see, et Bachmanni kass oli lahinguis talle alla jäänud ja Poest oli saanud kõikide kohalike kõutside hirm ja kiisude arm. Kassipulmade ajal istus kari kohalikke kõutse aia peal reas ja noolis Kirrit. Neid oli seal oma viis-kuus kassi. Kui Poe nähtavale ilmus, panid kõik kõutsid plehku. Järgmisi poegi Kirri enam maha ei murdnud. Osa neist olid üsna Poe moodi.

Poe oli kaval kass. Ta teeskles pidevalt magamist, et selle varjus oma tempusid teha. Hiirekesest ma juba kirjutasin. Ükskord olime poest vorsti ostnud. Oli laupäev ja sel päeval köeti Räpina alevi ühissauna. Mõtlesime, et enne sauna ei hakka vorsti sööma - pärast maitseb paremini. Külmkappi meil ei olnud ja ma ei mäleta, kas sel ajal neid üldse tavalisel inimesel juba oligi. Meil oli köögis toidu hoidmiseks vanaisa tehtud kapp, mis ulatus laeni. Ülemine riiul oli nii kõrgel, et hädavaevalt ulatus sinnani tooli peal seistes. Panime vorsti kõige kõrgemale riiulile, sulgesime kapiuksed. Sahvrisse ei tahtnud panna, sest seal oli palju hiiri. Vaatasime, et Poe magab suures toas diivanil. Sulgesime ka köögiukse.

Kui saunast tagasi jõudsime, magas Poe endiselt, nagu poleks midagi juhtunud. Aga köögiuks oli lahti, kapiuksed ka lahti ja vorst kadunud. Põrandal vedeles väike kassihammaste jälgedega vorstitükk. Pärast selgus, et Poe oli ära õppinud lingi peale hüpates köögiust avama. Uks avanes köögi suunas ja kui kass raskusega lingile hüppas, siis läkski see lahti. Seda, et ta sahvriust oskas lahti kraapida, me teadsime, aga köögiukse avamise oskusest ei olnud meil aimu.

Kui me Mitšurini tänavast uuesti Oktoobri tänavasse postkontori kõrvale suuremasse korterisse kolisime, me Poega enam kaubale ei saanud. Uuest korterist põgenes ta vana maja juurde. Külmade saabudes asus Poe elama Sieversi lossi keldris olevasse katlamajja. Temast sai parun von Sieversi lossi kass. Katlamaja lähe- 
dal keldris oli ka tehnikumi köök ja kokad andsid vahetevahel mõne pala ka Poele. Oli ta ju väga suur, uhke ja ilus kass. Käisime teda vaatamas seal aastaid, kuni ta kadunuks jäi.

\section{Ints}

Siinkohal jutustan veel ühe kassi loo. Selle rääkis mulle vanaema Mathilde. Vanaisa Johannes ning tema kaks venda Theodor ja Ferdinant olid auruvedurijuhid. Vanaisa ja Theodor abiellusid, aga Ferdinant suri poissmehena. Ta oli veel noor ja õppis Riias, kui ta kord kiirustades püüdis seisva rongi alt läbi pugeda. Rong aga hakkas ootamatult liikuma, ta jäi rongi rataste alla ja vagunirattad lõikasid tal pea otsast. Ferdinant maeti ühele Riia kalmistule.

Vanaisa ehitas maja Pärnumaale Mõisakülla Karja tänav 5. Perre sündis kolm tütart. Noorim tütar Ellen võttis endale ilusa vesihalli valge kurgualusega kassipoja. Kassi hellitati, silitati - nagu lapsed seda ikka teevad. Kass sai endale nimeks Ints. Ta elas toas.

Theodor elas koos naise Annaga härra Kiriku maja teisel korrusel. Ta oli ontlik mees, kandis kallist Inglise tviidülikonda, lipsu ja kalleid kingi. Õhtuti olevat ta keeranud oma pikad vuntsid vuntsikoolutajasse, et nad ikka ülespoole keeratuna seisaksid ja uhked välja näeksid. Ta jäi varakult leseks. Leskmehena armastas Theodor napsitada. Muidugi armastas ta seda teha ka enne Anna surma, aga pärast naise surma jõi rohkem. Ükskord, kui ta purjuspäi Johannese juurde tuli, lõi ta trepi peal lebavat kassi põhjuseta jalaga. Kassid, nagu teada, on pika vihaga ja ka see kass hakkas kätte maksma. Ta sirtsutas ja kakas mehe jalanõudele. Vana oli kassi peale tige, sest tema uhked kingad said määritud. Kui ta kassi kätte sai, pistis ninapidi kassiloiku või paksu sisse ja andis naha peale.

Kass Ints aga jätkas oma tempusid. Theodor pani jalanõud kapi otsa. Kui keegi ei märganud, ronis Ints jalanõudele kapi otsa järele ja sirtsutas need ikka märjaks. Vana Theodor oli hädas, aga mis sa teed.

Kui Theodori tervis elu lõpul väga viletsaks jäi, kolis ta lõplikult Johannese juurde. Vanaema Mathilde tegi siis mõlemale mehele süüa. Kõuts aga ronis Theodori voodisse ja lasi ka selle märjaks. Kassile anti naha peale, aga see ei aidanud. Nii kui tuppa pääses, ronis ikka Theodori voodisse sirtsutama. Lõpuks Intsu enam tuppa ei lastudki. Solvunult ronis kõuts pööningule, kraapis liiva pööningu põrandalt Theodori voodi kohalt ära ja lasi läbi lae otse 
voodisse. Theodor nihutas Johannese abiga voodi teise kohta. Keegi ei tea kuidas, aga kõuts aimas ära voodi asukoha, kraapis taas voodi kohalt liiva ära ja sirtsutas ikkagi voodisse.

Peale selle oli sellel kassil veel üks rumal komme. Ta istus alati põõsastes ja passis naabri kanapoegi. Ma ei tea, mitu tibu tal õnnestus ära süüa, aga ühel õnnetul hetkel tabas teda naabrimees, kes kassile kaikaga pähe lajatas. Löök oli nii tugev, et Ints heitis seepeale hinge. Vanaema pahandas küll naabriga, aga kass oli surnud mis surnud.

Theodor oli väga haige ja suri veidi hiljem. Kui naabrimees poleks Intsu maha löönud, oleksid kodused pidanud kassi ise maha lööma, sest kassi kättemaksust ei olnud võimalik teisiti pääseda.

See ei ole erakordne lugu kassi kättemaksuhimust. Peaaegu samasuguse loo rääkis mulle tädi Ellen. Kui ta oli Tõstamaal kooliõpetaja, elas kõrvalmajas Lõõbase perekond. Ka seal julges peremees kassi jalaga lüüa ja kordus täpselt sama lugu. Kassi lõpp oli ainult teistsugune. Vihane Lõõbas lasi kõutsi püssiga maha. Lõõbase tütred leidsid kassilaiba pööningult üles ja mees sai hurjutada.

\section{Krässu}

Kui elasime Mitšurini tänavas, tõi vend Lembit meile tillukese karvase valge kutsika. Koerake oli ilus ja krässus karvaga nagu mänguasi. Kutsikale pandi nimeks Krässu. Algas jälle üks nunnutamine, kallistamine ja paitamine.

Võhandu jõgi on Räpinas suletud pika tammiga, milles on neli lüüsikanalit. Kanalid olid kõik erineva suurusega. Esimesest kanalist jooksis vesi paberivabrikusse, teine oli suur pealüüs, kolmandast juhiti vesi vesiveskisse ja neljas kanal oli suure vee korral abikanaliks. Kolm esimest kanalit olid rekonstrueeritud. Sieversi lossi poolses otsas olev oli veel vana, rekonstrueerimata lüüs. Kanal ise oli umbes 50-70 meetrit pikk. Kanali seinad olid betoonist valatud ja kuni 10 meetri kõrgused. Kanali põrand oli puust ja seal lebasid ristipidi ümmargused palgid, millest lüüsist tulev vesi ülevalt ja alt läbi sulises. Sissepääs jõe poolt oli ainult pea- ja abikanalisse.

Abikanalis lebavate palkidega oli üks huvitav lugu. Lüüsist alla kukkuv vesi tõi endaga kaasa kalu. Väikesed viis vesi palkide alt läbi ja suured hüppasid palkidest üle, aga sellised parajad keskmise suurusega kalad jäid palkide alla kinni. See, kes poistest esimese- 
na kanalisse jõudis, sai öö jooksul palkide alla kogunenud kalad endale korjata. Vahel oli neid kalu üsna palju, kuni paar pangetäit. Teinekord olid ainult mõned üksikud kalad. Sellepärast tuli hommikul vara kalaleminekuga kiirustada, sest kes ees, see mees.

Ühel hommikul hästi vara läksin jälle kanalisse kalu korjama. Päike oli alles tõusnud, õhk oli jahe ja kaste maas. Krässu lipsas minu jalge vahelt läbi õue. Et kõik teised kodused magasid, ei tahtnud ma kolistada ja lasin tal endaga tulla. Ruttasime kanali äärde. Olin esimesena kohale jõudnud. Võtsin pikad püksid ära ja panin kanali betoonserva peale. Pange võtsin käe peale ja ruttasin kanalisse. Krässu jäi minu riiete juurde istuma.

Olin peaaegu kõik palgialused läbi vaadanud ja jõudnud peaaegu langeva vee alla, kui kanali äärelt hakkas kostma hirmsat vingumist, kiunumist ja lõrinat. Tormasin, pang käes, kanalist välja. Tormamiseks ei saa seda siiski nimetada, sest kanali põhi oli vetikatega kaetud ja seetõttu libe. Ka olid kanalilaudises kohati suured augud, mis takistasid kiiret liikumist. Minna tuli 60 meetrit. Siiski kiirustasin liialt ja lendasin paar korda istmikule. Vetikatest roheline ja märgade riietega, jõudsin lõpuks kanalist välja.

Pükste ja kingade juurde jõudes nägin läbinäritud kõriga verist Krässut maas lebamas. Kaugemal nägin jooksmas Allvere Reinu hundikoera, kes oligi selle kuriteoga hakkama saanud. Kahetsesin, et olin lasknud Krässul kaasa tulla.

Mis muud, surnud Krässu süles ja kalapang käes kiirustasin koju. Venna käest sain sugeda, et olin lasknud tema kutsika maha murda. Tulid järjekordsed lemmiklooma matused. Õed nutsid taas, aga teha ei olnud midagi.

\section{Musti ja tema poeg Pontu}

Kutsikas oli õdedele nii meeldima hakanud, et ühel päeval, natukene aega pärast Krässu surma tuli Johanna koju väikese musta kutsikaga. Tema pinginaabri koeral olid pojad ja loomulikult ei saanud ta kutsika pakkumisest keelduda. Koer ristiti Mustiks, sest ta oli tõepoolest nii must, et tal ei olnud valget laikugi karvastikus. Päritolult oli ta tõupuhas krants või - nagu minu sõbrad sakslased ütlevad segase koeratõu kohta - Strassenpromenade. Mustile tehti ase hoovipoolse ukse juurde eeskotta. Teisi kasse ta ei kartnud, aga kui Poe nähtavale ilmus, puges eeskoja nurka ning jäi vaikselt ja 
alandlikult vaiba peale kõhutama. Lapsed mängisid, koer kasvas. Eriti suureks ta ei kasvanudki. Kuigi kinkimisel öeldi kutsikas isane olevat, osutus ta emaseks.

Kolisime uude korterisse ja seal tõi Musti ilmale kolm poega. Kaks anti ära, aga mustjaspruun suurte pruunide käppadega kutsikas jäi meile. Valisime ta käppade järgi. Ema ütles, et kui kutsikal on suured käpad, siis kasvab temast suur koer. Loom sai nimeks Pontu, sest ta oli niisugune lontis kõrvadega ja nägi hale välja. Pontut hoiti toas, Mustit õues. Mustil oli see halb omadus, et ta ei pidanud puhtust, vaid lasi, kuhu sai, seepärast ei saanud teda toas pidada. Panime ta kuuri juurde ketti.

Mida vanemaks Musti sai, seda kurjemaks muutus. Omasid ei puutunud, aga võoraid kippus hammustama. Üks Räpina postiljon oli laisk mees ja võttis tihti ka viina. Ta ei viitsinud postkontorist tulles mööda tänavaid ümber kvartali käia, vaid lühendas oma teekonda läbi meie hoovi marssides. Muidugi tekkis tal tüli Mustiga, kes kiivalt oma territooriumi kaitses ja postiljoni peale raevukalt haukus. Kuid Musti oli ketis ja see tegi postiljoni julgeks. Mees võttis maast kepi ja lõi koera. Musti algul kiljatas ja siis hakkas veel raevukamalt haukuma. Vaatasime aknast välja ja nägime postiljoni Mustit togimas. Meie hõikamise peale lõpetas ta koera õrritamise ja läks oma postikotiga minema. Arvatavasti ei olnud see ainuke kord, kui ta koera õrritas.

Ühel päeval pääses Musti lahti ja hammustas postiljoni. Me ei teadnud sellest midagi. Tulime koolist ja nägime, et koer on lahti ja panime uuesti ketti. Mõni päev hiljem tuli meie juurde militsionäär Adamson. Ta ütles, et Musti oli postiljoni hammustanud. Rääkisime, et postiljon on pidevalt purjus ja torgib koera kepiga. Kõik lapsed kinnitasid, et on postiljoni koera narritamas näinud. Militsionäär kuulas meie jutu ära ja ütles, et teie koer oli lahti, kui ta postiljonile kallale läks. Ta hoiatas, et kui selline olukord kordub ja koer veel kedagi hammustab, siis on ta sunnitud meid trahvima. Tundus, et targem on Musti vaiksemasse paika toimetada. Viia Prits oli nõus Musti endale võtma, sest tema maja oli Köstrimäel metsa ääres ja hundid olid ta koera just minema viinud. Andsime koera Pritsule. Nii lõppes meie kooselu Mustiga.

Pontu kasvas suureks hagijaks. Ta ei mustanud kunagi tuba, vaid küsis ilusti välja. See oli nii naljakas. Mina magasin eestoas kušetil. Hommikul, kui Pontu õue tahtis, tuli ta minu magamisaseme juurde ja limpsis keelega üle mu näo. Limpsis seni, kuni ma 
silmad avasin. Näinud, et ma olen ärganud, hakkas ta ulguma: "Õuuu!" Kui ma silmi ei avanud ja teise külje keerasin, ronis ta kahe käpaga külje peale ja ulgus kõrva: “Õuuuu!” Ei olnudki midagi teha. Tuli üles tõusta, trepist alla minna ja koer õue lasta.

Vahel, kui ta päeval või õhtul õue küsis, narrisime vastu: "Ära ütle “Õuuu!", küsi “Õuuueee!” Meile vähemalt tundus, et ta sai aru ja hakkaski küsima: "Õuuuee!"

Pontu omandas kõik koerale vajalikud trikid. Ta andis käppa. Vahel tegi ta seda ilma ütlemata. Tulid koju, tema ootas juba rõõmsalt niutsudes koridoris. Siblis rõõmsalt ümber sinu siia-sinna. Siis istus maha, vaatas sulle otsa ja tõstis käpa üles. Parem ja vasak läksid küll segamini, aga tervitamiseks käppa pakkus ta siiski. Loomulikult kiitsin ma teda alati selle eest ja andsin vaevatasuks midagi maitsvat. Ta oskas sitsida. Ka omandas ta kahel käpal kõndimise. Kui ütlesid talle: "Pontu, tantsi!" ja kui ta tundis mingi maitsva asja lõhna, siis tõusis ta kahele käpale ja keerutas ennast mõned tiirud. Algul õpetasime teda nii, et pidime ise seisma, toidupala käes, ja siis ta keerutas ennast sinu käe all. Hiljem omandas ta ka iseseisva keerutamise oskuse.

Kui me terve perega suure ümmarguse laua ääres istusime ja sõime, vaatas Pontu vesise suuga pealt. Haugatades küsis ta endale ka palukest. Kuigi teda tavaliselt oli varem toidetud, oli tal hea isu. Muidugi andsid lapsed talle oma toidust paremaid palasid. Nähes, et keegi tema haugatamist ei kuula ja temast välja ei tee, tuli ta minu juurde, pani ühe käpa mu põlve peale ja ütles küsivalt: "Auhh!" Loomulikult andsin ma talle toidupala. Pontu läks järgmise lapse juurde ja kordas oma trikki. Ja jälle ei jäänud ta ilma. Nii kordas ta oma trikki kõigi kuue lapse juures.

Pontule meeldis palli mängida. Kui viskasid väikese palli kuhugi, otsis ta selle ülesse ja tõi sinu kätte tagasi, viskasid uuesti ja peagi oli pall jälle sinu juures. Õues loopisin keppi. Pontu otsis põõsaste vahelt kepi üles ja tuli sellega minu juurde, aga keppi ära ei andnud. Pidin seda tükk aega sikutama. Talle meeldis niisugune rahmeldamine. Lõpuks sain kepi enda kätte. Tegin, nagu viskaksin seda põõsaste suunas. Pontu tormas viske suunas, aga kui kepi kukkumist kuulda ei olnud, tuli minu juurde tagasi ja haugatas. Viskasin kepi kaugemale ja kõik kordus.

Musti ei jäänud kunagi vait, kui teda keelati. Kui aga Pontule ütlesid, et ei tohi või ole vait, sai ta kohe asjast aru ega haukunud rohkem. Kui ta kusagil õues oli, pruukis mul köögiaknast vilistada, 
kui Pontu läbi aia tuisates koju tuli. Teiste pereliikmete kutsumise peale ta iga kord isegi ei reageerinud, aga minu kutse peale ilmus alati kohale. Kui ta juurde tuli, pidi küsima: "Pontu, kus sa hulkusid? Häbi, häbi!" Seepeale vajus ta alandlikult maad ligi, tegi ennast väikseks-väikseks. Kui teda puutusid, viskas ennast selili ja ajas alandlikultjalad püsti.

Kui maasikad peenral valmis said, ei tohtinud Pontut hommikul vara üksi aeda lasta, sest ta sõi kõik ilusamad maasikad ära. Ka maitsesid talle ilusad punased suislepa ounad. Nendega ta algul mängis: näris natuke, viskas siis maha ja võttis uuesti suhu, aga siis, kui magus mahl suhu jõudis, sõi õuna ära. Kui andsid talle poole peale söödud õuna või kõigest õunasüdame, pani ta selle kohe nahka.

Tegin keskkooli ajal trenni - käisin jooksmas ja jalgpalli mängimas. Tavaliselt võtsin jooksule Pontu kaasa ja me jooksime pikki vahemaid. Käisime üle Kanajala soo ja jooksime üle põllu Naruskimäele ja tagasi. Seda maad oli edasi-tagasi oma kümme kilomeetrit. Vahel võtsin Pontu rihma otsa ja sõitsin jalgrattaga ringi, et koer joosta saaks. Käisin jalgrattaga Leevakul, Võõpsus, Verioral ja mujalgi.

Ükskord läksime Naruskimäele jooksma. Pontu jooksis minuga kaasa. Jooksime üle Rüütli maja taguse heinamaa. Pontu oli siis veel kutsikaohtu, kuigi kasvult andis suure hagija mõõdu välja. Heinamaal sõi lammas kahe utega. Pontu hakkas nende peale haukuma. Uted jooksid ema selja taha. Lammas taganes, aga sai millestki aru, et tegemist on kutsikaga, ja ta hakkas esisõrgu vastu maad kopsides Pontu suunas tulema. Mina olin juba mõnikümmend meetrit metsa suunas jooksnud ja jäin vaatama. Pontu algul haukus ja hüppas siia-sinna. Lammas ei andnud järele ja ründas Pontut. Kui lammas väga ligidale jõudis, hakkas Pontu niuksuma ja tormas hirmunult minu juurde. Ütlesin talle: "Häbi, häbi, kardad lammast, ise nii suur koer!" Pontu tõmbas saba jalge vahele ja vajus alandlikult maad ligi. Ta sai alati aru, kui teda kiideti või laideti.

Talvel käisin suusatamas. Ümbruskonnas ei olnud mingeid mägesid. Mäest sai alla lasta pastoraadi juures, alevi teises otsas vene kiriku juures ja viie kilomeetri kaugusel Naruskimäel. Tavaliselt valisingi viimase, sest nii tore ja rahulik oli läbi talvise metsa sõita. Oli veebruari algus. Loomulikult võtsin Pontu kaasa. Jõudsime Naruskimäele. Sõitsin ühelt poolt mäest alla ja teiselt poolt üles. Kui 
ma suure hooga mäest alla kihutasin, jooksis Pontu kõrval ja klähvis miskipärast hoolega, kui lumi talle vastu koonu tuiskas.

Hakkas hämaraks minema. Pöördusime Pontuga kodu suunas tagasi. Valisin ühe uue metsasihi ja liikusin seda mööda kodu poole. Sihti mööda liikumist takistas tuulemurruräga. Ka sihi kõrval oli siin-seal näha tormi murtud puid. Osa olid lausa juurtega ülesse kistud ja pikali heidetud. Metsast kostis imelikke häälitsusi. Ühest suunast kuulsin kumedat näugumist ja kusagilt kaugemalt rämedat möiratamist. Pontu jooksis põhiliselt minu kõrval, aga võõraid lõhnu tundes ja neid nuuskides kadus ta aeg-ajalt metsa ja tuli siis jälle tagasi.

Mööda sihti oli liikunud mingi loom. Tema ümmargused umbes 10-sentimeetrise läbimõõduga jäljed jooksid mööda sihti ja pöörasid paremale metsa. Pontu muutus neid nuuskides väga ärevaks. Aeg-ajalt ta kiunats ja tormas siis jälgi mööda metsa. Mina liikusin mööda metsa edasi. Korraga hakkas koer raevukalt haukuma. Samast kostis ka tumedaid turtsatusi. Kutsusin Pontut, aga ta ei tulnud ära. Sõitsin läbi tuulemuuru ja nägin kase harude vahel kikkis kõrvadega looma. Kõrvad lõppesid ligi 5 sentimeetri pikkuste tuttidega. Looma põski kattis sorgus habe. Loom urahtas puu otsas. Tundsin kohe ära, et see oli ilves. Kartsin, et ta hüppab puu otsast koerale või mulle pähe ja kutsusin koera ära. Pontu tuli minuga vastumeelselt kaasa, mõned korrad tagasi joostes ja ilvest haukudes. Hiljem sain teada, et ilves ei hüppa kunagi saakloomale puu otsast selga, nagu inimesed temast räägivad. See on ainult rahvajutt. Ilves jälitab saaki joostes nagu koer. Loomale ligi jõudes alustab ta hiilimist. Maadligi roomates hiilib ta lähemale, kuni tabab saagi mõne pika hüppega. Kui saakloom ikka põgenema pääseb, ei hakka ilves teda jälitama, vaid otsib uue saaklooma. Sattusime ilvese lähedusse tema jooksuajal, mis on jaanuarist märtsini. Rämedam hääl kuulus isailvesele, kes oli ka metsas kusagil meie läheduses.

Kiirustasime koju. Metsas käimine ja jahipidamine saigi Pontule saatuslikuks. Vanemaks saades hakkas ta üha rohkem metsa poole vaatama. Käisime ise koolis ja hoidsime teda toas või panime ketti, kuid Pontu oskas kaelarihma ikkagi üle pea tõmmata ja jooksis jälle metsa. Paar korda tuli ta metsast tagasi, pea või külg verine haavlilaengud keres. Kaks haavlit olid tal jäänud peanaha ja kolju vahele, nii et koera pead paitades oli neid sõrmeotstega tunda. Haavlite puudutamine tegi talle valu, sest siis hakkas ta niutsuma 
ja tõmbas pea ära. Korra oli ta mitmeid päevi kadunud ja siis ilmus nähtavale longates, traatsilmus jala küljes. Ta oli metsas luusides silmusesse jäänud, kuid mingil moel õnnestus tal silmusetraat läbi närida. Aga lõpuks ta jäigi kadunuks.

\section{Siilike}

Ühel suvel pobises meie aias väike siilpoeg. Vaatasin ringi. Emasiili ja teisi siilipoegi ei olnud näha. Püüdsin siili kinni ja panin heinte peale puust kasti. Kasti viisin puukuuri. Toitsin siili piima, vihmausside ja konnapoegadega. Siilike kasvas ja oli sügiseks juba päris vana siili moodi. Ta harjus minuga. Kui ta algul peo peale võtsin, tõmbas ta ennast kerra, turtsus ja ajas okkad püsti. Hiljem enam ei tõmmanud ega ajanud isegi okkaid turri.

Ühel päeval tõin talle suure konna. Imelik oli see, et siil ei tapnud teda ära, vaid hakkas elusast peast tagajalast alustades sööma. Konnal ei olnud kastis võimalik kuhugi põgeneda. Ta sikutas oma jala lahti ja hüppas kasti teise serva. Siil läks järele ja haaras jälle jalast kinni. Mingil hetkel hakkas konn peenikese häälega karjuma. Kuulsin elus esimest korda, et konn teeb sellist häält. Võtsin kasti ja kallasin selle sisu põõsa alla tühjaks. Siil sõi oma saaki rahulikult edasi. Kuni hilissügiseni elas ta meie aias ja tuli õhtuti alustassi pealt piima jooma. Hilissügisel, kui ilmad külmaks läksid, puges ta kuhugi urgu magama. Kevadel ma teda enam ei näinud.

\section{Minu rebasepojad}

Lõpetasin Räpina keskkooli ja läksin enne ülikooli minekut aastaks tööle. Üheks minu töökohaks oli Pärnu Metsakombinaat. Olin seal vaigutaja. Minu vaigutuspiirkond oli Pärnu-Jaagupi taga Laaksaare lähedal. Tõusin hommikul vara. Õhk oli siis jahedam ja vaigukanalite lõikamine läks jahedas libedamini. Tihti ma päevaks koju ei tulnud, vaid sõin oma lõunaleiva metsas. Palaval lõunaajal jalutasin ma metsas ringi ja vaatlesin loodust.

Üsna oma vaigutuslangi lähedalt leidsin rebasepesa. Algul arvasin, et tegemist on mägrakoopaga. Uru suudmesse oli kuhjatud suur liivavall ja suue oli pikendatud vaokujulisena liivahunnikus- 
se. Koopal oli mitu väljapääsu. Vaatasin jälgi, aga need olid liiga väiksed. Hakkasin seda pesa jälgima. Käisin iga päev pesa juures ja istusin põõsa varjus. Nägin, kuidas vana rebane hiilis urgu, midagi hambus, ja tuli natukese aja pärast urust välja. Seega oli rebane mägrauru üle võtnud. Paari nädala pärast oli märgata uru juures askeldamist ja selgus, et rebasel on pojad. Vana rebane läks ära. Tulin uru juurde ja jäin vaikselt istuma. Umbes poole tunni pärast oli kuulda krabinat. Pesast tuli välja väike rebasekutsikas. Ta vaatas uudishimulikult ringi. Tuul oli tema poolt minu suunas ja ta ei näinud mind. Siis tuli urust veel kaks kutsikat. Nad hakkasid uru ees mängima. Üks nendest tuli mänguhoos mulle liiga lähedale, tundis mu lõhna, haugatas ja tormas koopasse. Teised vudinal järel.

Mingi aja pärast hakkas emarebane tooma poegadele poolelusat saaki. Ta tõi mitmesuguseid linde, jänesepoegi ja ükskord isegi noore kana. Pojad ei murdnud neid kohe maha, vaid harjutasid murdmisvõtteid.

Otsisin metsast pasknääri, hoburäästa ja varese pesi, võtsin sealt linnupoegi ja tõin oma saagi rebasepoegadele. Lasin pasknääripoja uruavast sisse, ise ronisin peitu. Varsti oli kuulda krõbinat. Rebasepoeg tuli, pasknäär hambus, pesast ja hakkas linnuga mängima. Tema järel tormasid pesast välja teisedki. Lõpuks harjusid rebasekutsikad minuga. Andsin neile oma leiva ülejääke ja tõin korteriperenaise kanakuudist kanamune.

Kuu aja pärast kohtasin rebasekutsikaid juba mõnesaja meetri kaugusel pesast. Mind märgates tormasid nad ummisjalu pesa poole. Kui ma pesa juurde maha istusin ja nad mu ära tundsid, tulid nad üsna lähedale. Tõin neile alati süüa kaasa.

Otsustasin minna metsandust õppima. Mul oli tunne, et igal metsaülemal on kõik tema metsa loomad sõbrad, nagu minul olid omad rebasepojad. Eksamid tegin edukalt ja septembris lahkusin vaigutajaametist ja kolisin Tartusse.

Järgmisel suvel külastasin oma korteriperenaist ja läksin ka rebasepesa vaatama. 1967. aasta augustitorm oli teinud minu vaigutuslangil laastamistööd. Kännud seisid, juured püsti nagu tankitõkked. Männitüved olid juba ära saetud ja minema veetud. Ka rebasepesa ümbrusest oli mets maha raiutud. Rebasepesa oli maha jäetud - selle lähedal ei olnud ühtegi värsket rebasejälge.

Pärast kõrgkooli lõpetamist tööl olles selgus, et metsamees tegeleb kõige muu kui oma piirkonna loomadega sõbrustamisega. 


\section{Innogeli}

1970. aasta jaanuaris sõitsin tšuktšide maale. Nad elasid Magadani oblastis Anadõri lisajõe Maeni ääres Vaegi külas. Olime sõbraga kohanud Peterburis õppivaid noori tšuktši neide, kes meid pärast ülikooli lõpetamist külla kutsusid ja me ei suutnud minemata jätta. Vaegis kujunes meil hea läbisaamine kõikide kohalike noorte, eriti aga tšuktši tüdrukutega.

Ühel õhtul koputati minu uksele. Ukse taga seisis kena tšuktši neiu, kes tahtis minuga juttu ajada. Ta oli Markovos käinud ja saanud sealt alkoholi osta. Tšuktšimaal kehtis nimelt kuiv seadus ja alkoholi müüdi rahvuskülades ainult riigipühadel, seepärast arvasin, et miks ka mitte, tulgu neiu külla, kui tal sellised soovid on. Pealegi oli minu sõber Eerik Eestisse tagasi sõitnud ja ma olin üksi kodus. Markovo on Vaegist 300 kilomeetri kaugusel lõuna pool asuv vene küla. Seal käidi lennukiga, mis käis Markovo ja Vaegi vahet kaks korda nädalas, muidugi kui lennuilma oli. Palusin neiul kasuka seljast võtta ja laua äärde istuda. Panin lauale seda, mida oli. Suurt midagi panna ei olnud, sest poes olid müügil ainult kuivproduktid - kuivatatud sibul, kuivatatud kartul, makaronid, tangained. Muidugi oli aeg-ajalt saada ka kalakonserve. Liha ja lihakonserve, võid, vorsti ega värsket kala ei olnud kaupluses peaaegu mitte kunagi, kanamune müüdi kaks tükki igale inimesele nimekirja järgi.

Peale kaupluse oli võimalik saada toitaineid ka kolhoosi laost. Laohoidjaks oli üks belamuud. Vladimir Bogaraz-Tan mainib oma raamatus Tšuktšid neid kui Valge mere naise jöreltulijaid. Minu Vaegi-külastuse ajaks olid nad muutunud belamuudideks. Näiteks Miša Bogrtšov, keda ma mitmes oma loos maininud olen, oli nn belomorski tšuktš, kes nimetas ennast belamuudiks. Korjakid ja tšuktšid kutsusid belamuude ka valgeteks juutideks. Seda ühelt poolt seetõttu, et nad olid rohkem kui teised kohalikud hõimud segunenud europiidse rassiga, põhiliselt venelastega, millele hiljem aitas kõvasti kaasa Üleliidulise Kommunistliku Noorsooühingu löökehitus - Bilibino aatomielektrijaama rajamine Tšuktsi poolsaarele. Teiselt poolt oli neil rohkem ärilist vaistu, nagu näiteks kolhoosi laohoidjal, kes oli teeninud ära hüüdnime Karvalõt (eesti keeles 'hangeldaja', vene ajal kutsuti neid ka spekulantideks), kes oli samuti rahvuselt belamuud. 
Tema oli välja mõtelnud kavaluse, kuidas saada 5 rubla ja 60 kopikat maksva piiritusepudeli eest kõrgemat hinda. Selleks rääkis ta kõigile suurest õnnetusest, et tal on laos arvel lehmapea, mis on eksituse tõttu arvel nagu lehmaliha. Ta palus tšuktši, kes soovis osta pudeli piiritust, teda aidata ja osta ära see lehmapea, muidugi lehmaliha hinnaga. Lehmapea oli üsna raske ja nii kujunes piiritusepudeli hinnaks 103 rubla ja 50 kopikat. Tavaliselt ei olnud alkoholinäljas mehel kelku kaasas ning lehmapea jäi lattu vedelema, kus ta järgmisele mehele mõnel teisel päeval taas maha müüdi. Nii tegi see lehmapea küla joodikutele oma paar tiiru peale, sest keegi ei viitsinud seda käe otsas minema viia.

Lõpuks üks vanamees vihastas, sest teda sunniti kolmandat korda seda haisvat lehmapead ära ostma. Ta tõi kelgu. Külaelanike naeru ja hõigete saatel vedas vanamees lehmapea küla prügimäele, kuhu ta selle hulkuvatele koertele ja muudele loomadele söögiks jättis. Pean siinkohal ütlema, et isegi kolhoosi hobused olid prügimäel sagedased külalised ja ära ei öelnud nad isegi prügimäele visatud surnud koertest.

Karvalõti käest olin ostnud, loomulikult poole kallima hinnaga, kümmekond hautatud loomaliha ja "Turisti eine" konservi. Panin need lauale. Ka panin lauale neli teeklaasi ja tükisuhkru. Olin enne köögis süüa teinud. Pliit oli kuum ja pliidi peal oli ka pada kuuma veega. Tegin kannu teed ja tulin köögist tuppa. Neiu võttis käekotist pudeli Subrovkat. See jook oli Venemaal levinud ja Nõukogude ajal müügil ka Eestis. Jook oli tehtud viinast, millele oli lisatud tarna, mis andis alkoholile pruunika värvuse. Muidu oli see kibeda maitsega, aga tarn võttis viina maitse vähemaks.

Kallasin teeklaasi põhja natukene Subrovkat. Neiu tutvustas ennast Nadeždana. Mina tutvustasin ennast Jelona. Neiu hakkas naerma ja ma ei taibanud miks. Alles mõned kuud hiljem sain teada, miks ta naeris. Jelo on nimelt tšuktši keeles ka majasõber või abieluliidu meessoost liige.

Ütlesin toosti: "Võtame meie tutvuse ning heade ja ilusate lootuste terviseks (nadežda tähendab vene keeles 'lootus').

Korraga kostis välisukse tagant kraapimist ja kiunumist. Tegin ukse lahti ja seal oli kõige ilusam laika, keda ma elus näinud olin. Ta oli suurem kui hundikoer. Värvuselt must, valge kaeluse, rinnaesise ja valgete käpaotstega. Ka Nadežda tuli koridori. Koer hakkas teda nähes rõõmsalt niuksuma ja tuli meie juurde korterisse. Nadežda tahtis ta uuesti õue viia ning ütles: 
"Noor koer, jooksis mulle kodunt järele. Jätsin ta küll õue, välisukse taha, aga keegi lasi koridori."

Vastasin: "Las jääb siia, meil siin maja ümbruses mõned venelased tapavad nugadega kõik koerad, kes maja lähedusse satuvad."

"Miks nad seda teevad, koer on inimese sõber."

"Tundras olevat hulkuvad koerad neid rünnanud, nüüd on nad kõigi koerte peale tigedad. Aga mis su koera nimi on?"

"Innogeli."

"Mida see nimi tähendab?"

"Valgekael."

Mõtlesin, et geli kirjutatakse keli, mis tundus väga eesti kaela sarnane. Küsimisel selgus, et kael on tšuktši keeles inn, valge lumine mäetipp aga gel. Kel on hoopis naba. Jäähammas või jääpank meres, ka valge merejää on gelgel. Samas olevat igal lumestruktuuril ja varjundil oma nimi. Meri ise on tšuktši keeles anga, mereäärne elanik angalön, paha merevaim anga-kail.

Andsin Innogelile leiba ja koer sõi seda väga aplalt.

Küsisin, miks koer toitmata on. Nadežda vastas, et koeri ei tohi ära hellitada. Kui koer rakendada narta ette, peab ta olema harjunud jooksma paar päeva söömata, sest pikale reisile ei jõua palju toitu kaasa võtta. Selgus, et tšuktšid toidavad seetõttu oma koeri ainult üks kord päevas - õhtuti. Koertele antakse söögiks põhiliselt kala. See võib olla toores, külmutatud või ilma soolata kuivatatud kala - jukola. Reisil olles püütakse liikuda ka neis piirkondades mööda jõge, kus maa sisse on ladustatud will-will. See on hülgenahast kotti pandud kala, mis on valatud üle põdraverega ja maetud maa sisse. Kala läheb mädanema ja seda söövad nii koerad kui ka inimesed. Olin seda ka varem Vasja Startsovi käest kuulnud, aga päriselt ei uskunud. Hiljem kirjandust uurides selgus, et seda kisluju rõbu (vene keeles 'hapu kala') kasutas kevadperioodil söögiks enamik põhjarahvaid ja ka põhjas elavaid muulasi (Bobretsova 2001: 147-168; Kartašov 1959: 15; Siimets 1999: 130-137).

Mereäärseid tšuktšid toidavad oma koeri peale kala ka mereloomade, näiteks hülge, morsa või vaala sisikonna ja rasvaga. Kui koerad on terve suve vabapidamisel ja neile antakse piisavalt toitu või söövad nad kaldale uhutud ketade laipu, siis enne narta ette rakendamist jäetakse nad dieedile. Koertele ei anta siis kolme-nelja päeva jooksul üldse süüa. Mõned tšuktšid rakendavad oma koerad sügisel, kui lumi veel maas ei ole, paariks päevaks narta ette ega anna siis koerale ka üldse süüa, et harjutada teda rakendiga. 
Mõned koerarakendi juhid rakendavad kevadel sündinud koerad juba sügisel kelgu ette, et neid sellega harjutada. Ema rakendatakse kõige ette ja kutsikad järele. Sellisest kombinatsioonist pidi saama väga hea koerarakendi meeskond.

Vestlesime ka paljudel muudel teemadel, aga sellest mõnes teises artiklis.

Nadežda jäi minu juurde ööbima. Innogeli magas voodi ees põrandal. Hommikul jõime teed ja einestasime. Andsin ka koerale mõne pala ja sain neiu käest pahandada, et rikun koera ära. Läksin hommikul tööle. Nadežda ja Innogeli läksid koju.

Kaevasime oma ehitusbrigaadiga selle maja kõrvale, kus mina elasin, uue maja vundamendipostidele auke. See oli raske töö. Raudkangiga tuli pinnas lahti raiuda ja siis lahtiraiutud pinnas kühvliga august välja visata. Õhtuks käed küünarnukkidest ja randmetest lausa valutasid. Sellistel puhkudel meenusid mulle Eeriku vanemate sõnad, kes ütlesid, et teised saadetakse Magadani oblastisse sunnitööle, aga teie lähete sinna vabatahtlikult. Nii see oligi. Töö oli tõepoolest nagu sunnitöö, aga palka maksti hästi. Aeg-ajalt istusime augu äärele mullahunniku peale pandud lauatükkidele puhkama. Tegime suitsu ja vaatasime ringi. Siis ronisime jälle auku, raiusime igikeltsa ja kõik kordus.

Järgmise päeva õhtupoolikul, kui me järjekordselt puhkasime, nägin tuttavat koera mööda külateed jooksmas. Vilistasin ja hõikasin: "Innogeli!" Ta vaatas meie suunas, aga kuna ka minu brigaadi mehed istusid mullahunnikul, jooksis algul meist mööda. Läksin teele lähemale ja hõikasin uuesti. Innogeli pööras ümber ja jooksis minu juurde, vaatas mulle küsivalt otsa ja liputas saba. Silitasin tal pead ja kutsusin endaga kaasa. Läksime meie korterisse ja ma andsin talle leiba loomalihakonservi rasvaga. Talle meeldis see ja ta kugistas leiva kiiresti alla. Tõstsin talle ette eelmisel õhtul keedetud tatraputru ja see kadus ka nagu vesi kuumalt keriselt. Läksime õue. Järgmisel päeval tuli Innogeli ise minu juurde. Andsin talle taas süüa. Nii hakkaski ta minu juures käima. Mõni õhtu tuli ka Nadežda minu poole. Ega siis Innogeligi maha jäänud. Nadežda pahandas, et Innogeli on hulkuma hakanud. Ma ei saanud öelda, et tegelikult on ta väga palju meie juures ja aeg-ajalt ööbib minu voodi ees.

Siis saadeti Nadežda kaheks pooleks kuuks Magadani täienduskursustele. Innogeli jäi Vaegi ja hakkas elama meie juures. Laupäeval ja pühapäeval käisin kalal või jahil ja koer saatis mind alati. 
Õpetasin talle eestikeelseid käsklusi: istumist, lamamist, jala kõrval seismist ja kõrval kõndimist. Kui ta käsu täitis, andsin talle mõne toidupala ja loomulikult sai ta süüa iga kord, kui ta meile tuli. Õpetasin talle ka eesti koerte vigureid: sitsimist, käpaandmist, haukumisega toidu küsimist. Ta omandas kõik need kaunid kunstid. Isegi kepi otsimise ja tagasitoomise sai selgeks. Üldiselt tšuktši koerad eriti ei haugu, aga nad uluvad öösiti haledalt. Kui mõnel kuuvalgel ööl hakkas kusagil hunt või koer uluma, ühinesid temaga varsti kogu küla koerad. Selline ulgumine võis kesta mitu tundi.

Nagu ma kirjutasin, oli Innogeli suur, ilus, tugev koer. Kui me tänaval kõndisime, ei teinud ta teistest koertest välja. Kui näitasin Innogelile käega teise koera peale ja ütlesin talle tšuktši keeles yan (nii anti koerale suund liikumiseks), tormas ta võõra koera peale, surus end urisedes vastu maad ja siis vaatas mulle küsivalt otsa, et kas ta peab jätkama või kuidas. Kui ütlesin tuugu mis tähendas 'võta', tegi ta teisele koerale ka haiget, muidu piirdus urisemisega. Eestikeelsest käsklusest "Tule ära!" sai ta väga hästi aru, jättis teise koera lamama ja tuli minu juurde. Ütlesin "jalg", ja ta kõndis minu kõrval.

29. mail läksin praami peale madruseks. Praam peatus katlamaja juures sadamas. Seal oli üks küla kõrgemaid kohti. Kui ümbruskond oli üleujutuse tõttu vee all, siis katlamaja juures oli küngas veest väljas. Laevakapten tšuktš Innokenti ei lubanud koera kaasa võtta, sest laeva peal oli juba tüürimees Sanjale kuuluv valge kutsikas ja ta kartis, et suur koer murrab väikese maha. Mehed peal, asus praam popsutades mööda jõge allavoolu teele. Innogeli jäi niuksudes sadamasse. Vedasime saematerjali Anadõri ja Maeni jõe ristumiskohast Vaegi. Üks reis kestis kümme päeva. Kolm päeva sõitsime laadimiskohta, neli päeva laadisime saematerjali, kolm päeva sõitsime tagasi. Tagasi jõudes sõitis praam Vaegi keskväljakule. Küla oli veel üleujutuse tõttu vee all ja seetõttu selline reis võimalik. Praam laaditi keskväljakul tühjaks ja saematerjal kinnitati trosside ja nööride abil elektripostide külge. Kui vesi nädala pärast alanes, oli saematerjal lossitud õigesse kohta - selle maja lähedale, mida me väljaku kõrvale ehitasime.

Innogeli oli sadamas meid oodanud, tundis meie laeva mürinast ära ja tormas laadimiskohta. Pärast praami tühjendamist läksid kõik kodudesse, et järgmisel hommikul uuesti teele asuda. Söötsin Innogelil kõhu täis. Mängisime palli toomist ja ma tuletasin talle eestikeelseid käsklusi meelde. 
Õhtul nägime kõrvalkorteris elavat katlakütjat Ivani. Kuna jõgi oli jääst puhas, oli poes alkoholi vabalt saada. Ta oli ostnud kaks Pliska konjakit ja tuli meile külla. Tipsutasime konjakit (Ivan lasi muidugi klaasist ja kulinal) ning ajasime juttu. Ivan rääkis, et Innogeli oli kõik need päevad katlamaja kõrval mind oodanud ja niutsudes selles suunas vaadanud, kuhu praam oli kadunud. Ta oli sadama juures künkal ka ööbinud. Ivan oli talle kodust süüa toonud. Kui praami mürinat oli kuulda, oli Innogeli püsti karanud ja rõõmust kiljuma hakanud. Siis tormas ta läbi vee küla keskväljaku suunas, kuhu praam suundus. Tegin Innogelile pai ja kiitsin teda.

Hommikul läksime jälle praamile ja sõitsime kauba järele. Innogeli jäi niutsudes sadamasse. See oligi viimane kord, kui me teda nägime. 12. juunil oli Nadežda Magadanist tagasi. Ta sõitis 15. juunil helikopteriga põhjapõdrakarja juurde ja võttis Innogeli endaga karja kaasa. Saabusime kaks päeva hiljem ja seda koera ei näinud ma enam kunagi.

\section{Kirjandus}

Bobretsova, Aleksandra 2001. Petšora alamjooksu vanausuliste toitumissüsteem ja traditsioonid. Anepaio, Terje (toim). Eesti Rahva Muuseumi aastaraamat $=$ Yearbook of Estonian National Museum $=$ Jahrbuch des Estnischen Nationalmuseums = Ежегодник эстонского национального музея XLV. Tartu: Eesti Rahva Muuseum, lk 147-168.

Kartašov 1959 = Карташев, Борис И. По стране оленных людей: Путешествия B. Г. Тана-Богораза. Замечательные географы и путешественники. Москва: Географгиз.

Siimets, Ülo 1999. Tšuktšid II. Mäetagused: Hüperajakiri 12, lk 130-137 (http://www.folklore.ee/tagused/nr12/tsukts.htm - 15. detsember 2005). 